\title{
The Commitment to Care
}

Countless are the opportunities in which we hear patients asking: "Will you take good care of me?" Although naïve in context, it is, however, full of meaning and commitment. It is the cornerstone of the decanted doctor-patient relationship. Patients come to us hoping that we can give them back their lost vitality and some extra time of existence. They rely on us, and from the moment we accept this trust, whatever the reason, a process is started between two human beings to be guided by solidarity, respect, and compassion.

Strictly speaking, ethics does not need to be written or stored on any flash drive. It goes beyond the text, whether printed or transformed into electrical impulses displayed by LCD screens. It just records the obvious regarding the conduct to be adopted in a particular social or professional group, especially if the focus of the activity is taking care of others. Ethics should be intrinsic to each individual who is committed. A careful reading of articles and paragraphs of the Code of Medical Ethics, which expound on the relationship between physicians and their patients, allow us to conclude that it only informs the obvious regarding the proper conduct when dealing with human beings. In clinical research, these principles are even more implicit; concepts like generosity expand the process to the benefit of others. The quest for notoriety, personal and professional promotion or financial profit unfortunately corrupts the principles and betray the patient's trust, witnessed at signing the informed consent. In fact, this signature does not (and never did) exempt clinical researchers to deviate from what ethics precepts and from the agreements based on it. The supervisory boards of medical practices formed by peers would be unnecessary, if not for so many diversions and lack of commitment to the principles that should be obvious.

Florence Nightingale, in the nineteenth century, created the recovery room for patients undergoing surgical procedures. She probably got tired of seeing so many deaths and complications in the immediate postoperative period due to lack of proper care. From that point on, a differential was established: the obligation and the need for intensive care of patients undergoing surgical procedures. Today, in the twenty-first century, this discussion has become passive. One can easily deduce that, for solidarity, respect, and compassion reasons, patients undergoing surgical procedures (adults or children) should receive special care in the immediate postoperative period because, as noted Lady Nightingale, these people may have smaller chances. Many small, medium, and metropoli$\tan$ Brazilian cities are still offering surgical assistance without offering post-anesthetic recovery rooms. This fact displays of flagrant disregard for the law. This situation can be seen as unethical by this and the other reasons mentioned above. Every professional involved with surgical procedures, as a matter of ethics, should ensure to the patient the resource of the recovery room after anesthesia, independent of written codes, laws, and agreements required. It has little use without the physician's sincere commitment to the patient under his care. Currently, the reality seen by Nightingale 200 years ago remains the same. Statistics show a considerable number of complications occurring during the first hours after surgery. Reports are lavish in describing possible complications in the recovery room after anesthesia. In his first year of residency, a resident physician in anesthesiology will proudly display his newly acquired knowledge, enumerating from "hypothermia" to "residual curarization". Three years later, however, with the certificate under his arm, after anesthetizing a "belly", "a femur," or a "cesarean," he forgets everything and leaves the patient, of whom he did even know the name, to his fate, half conscious, in pain, on a bed of any ward. How often absorbed with his newly acquired tablet or cell phone does he leave the patient already abandoned during surgery?

There has always been a certain conflict between scientific advancement and human development. Nowadays, the rapid growth of technology has boosted the scientific advance in equal proportion. New ways of thinking and acting in these areas require new behaviors on the part of society - to some extent shrouded by perplexity resulting from the speed of changes. This requirement has given rise in the 70 s to the concept of bioethics, broadening the spectrum of ethics in biological sciences. This is perhaps a desire somewhat pretentious to join in a single discipline the philosophy and science involving life. Its mottos range from respect for patient autonomy in their choices, even for proposed treatments, to the universal distribution of the health services benefits through the obligation of good and repudiation of evil. In court, the disregard and violation of these aspects can be named negligence and recklessness.

The red-lights can not be surpassed only because the law forbids. They exist so that everyone can travel safely and orderly.

Ethics is something that is implied. It does not need to be written to be exercised. Codes of Ethics would be unnecessary if we had implicit respect, solidarity, and compassion for those who entrust us with their lives - their highest good.

Mario J da Conceição, MD, MSc, PhD Editor in Chief 